\title{
Risk Factors for Congenital Deafness in Pediatric Patients Who Underwent Otoaccoustic Emission (OAE) and Auditory Brainstem Response (ABR) Examinations in General Hospital Mohammad Hoesin Palembang, Indonesia
} Fiona Widyasari' ${ }^{1}$, Fani Paulina ${ }^{*}$, Ahmad Hifni1 ${ }^{1}$, Abla Ghanie ${ }^{1}$, Erial Bahar1

${ }^{1}$ Department of Ear Nose Throat Head and Neck Surgery, Faculty of Medicine, Universitas Sriwijaya, Palembang, Indonesia

\section{A R T I C L E I N F O Keywords: \\ Congenital Hearing Loss \\ Hearing Screening \\ Otoacustic Emissions \\ Auditory Brainstem Response \\ *Corresponding author: \\ Fani Paulina \\ E-mail address: \\ Fani.paulina@yahoo.co.id}

All authors have reviewed and approved the final version of the manuscript.

https://doi.org/10.32539/bsm.v5i8.341

\begin{abstract}
A B S T R A C T
Background: Congenital deafness is a hearing loss that occurs at birth. Congenital deafness in neonates can be caused by risk factors during pregnancy and during the birth process. The tests carried out for hearing screening for neonates in hospital up to 1 month old are Otoaccoustic Emission (OAE) and Auditory Brainstem Response (ABR) examinations. Objective: Determining the relationship between family history of deafness, syndromes associated with sensorineural hearing loss, TORCH infection and prenatal syphilis, use of ototoxic drugs during pregnancy, prematurity, low birth weight, asphyxia, and hyperbilirubinemia with the incidence of congenital deafness in children Methods: This cross-sectional study was conducted based on medical record datas from children who underwent OAE and ABR examinations at Dr. Mohammad Hoesin Palembang hospital from January 2019 to February 2021. Results: From the 349 children, 180 (51.6\%) had bilateral OAE and ABR pass results, $161(46.1 \%)$ had bilateral referrals and $8(2.3 \%)$ children received unilateral refer results. From 122 children with risk factors, $38(31.1 \%)$ children with bilateral passes, $81(66.4 \%)$ children with bilateral referrals and $3(2.5 \%)$ children with unilateral refer. From 227 children without risk factors, $142(62.6 \%)$ children with a bilateral pass, $80(35.2 \%)$ children with bilateral referrals and $5(2.2 \%)$ children with unilateral refer. The most common risk factor was LBW of $41(11.7 \%)$ children. Chi square test and logistic regression analysis results showed a significant relationship between ototoxic drugs during pregnancy and congenital deafness $(p=0.001)$ with referral results, the value of Odd Ratio (OR) 9.651. Conclusions: There is a significant relationship between risk factors for ototoxic drugs during pregnancy, TORCH and syphilis infection during pregnancy, asphyxia, congenital syndrome, LBWand hyperbilirubinemia with congenital deafness.
\end{abstract}

\section{Introduction}

Congenital deafness hearing loss that occurs at birth. This deafness can be either partially deaf (deaf) or totally deaf (deaf). Congenital deafness in neonates can be caused by risk factors during pregnancy and during the birth process. The screening for hearing loss in hospitals is divided into Universal Newborn Hearing Screening (UNHS) and Targeted Newborn Hearing Screening (TNHS). Based on UNHS guidelines issued by the Joint Committee on Infant Hearing (JCIH) in 2007, the tests carried out for hearing screening in hospital neonates up to 1 month old are Otoaccoustic Emission (OAE) and Auditory Brainstem Response (ABR) examinations. ${ }^{1,2}$

The incidence of hearing loss in newborns in developed countries is between 1-3 per 1000 healthy neonatal births and 2-4 per 100 neonatal births admitted to the NICU. Hearing sensory health survey data in 7 provinces from 1994 to 1996 stated that $0.1 \%$ of the population suffered from deafness from birth. UNHS data shows the incidence rate is estimated at 1.33 out of 1.000 live births experiencing bilateral 
deafness. In Indonesia, January 2010 to March 2012 the ENTKL Community division of the ENTKL Department of the FK UNSRI / RSMH found bilateral types of deafness as much as $80.8 \%$ (365), unilateral deafness was $19.2 \%$ (87) in children who experienced speech delays. The most cases obtained are sensorineural deafness and generally children come for treatment over the age of three years. Director General of Disease Prevention and Management, Ministry of Health of the Republic of Indonesia through a circular number HK. 02.02 / V / 553/2017 concerning the Commemoration of World Hearing Day 2017 called for the prevention of hearing loss and deafness at least in the form of campaigns related to the prevention and control of hearing loss and deafness, as well as screening and early detection of hearing loss in newborns and school children through school. , and Posbindu Non-Communicable Diseases. 3-6

High-risk neonates according to the JCIH are recommended to identify the possibility of congenital or acquired hearing loss, including family history of congenital deafness, ear and craniofacial anomalies, intrauterine infections associated with sensorineural hearing loss (infection with toxoplasmosis, rubella, cytomegalovirus, herpes and syphilis). physical-related syndromes known to be associated with sensorineural hearing loss, perinatal risk factors such as low birth weight, prematurity, hyperbilirubinemia, asphyxia, use of mechanical ventilation for 5 or more days, and ototoxic drugs given for more than 5 days or use as a combination with a loop diuretic. Infants with one or more of the risk factors listed above should undergo a hearing evaluation within the first 2 months of life and continue to be evaluated further even if the results are normal. Babies with 1 risk factor have a 10.1 times greater likelihood of suffering from hearing loss than babies without risk factors, babies with 2 risk factors have 12.7 times the likelihood, whereas if there are 3 risk factors, the likelihood increases to 63.2 times. ${ }^{1,2}$

In a study in India, hearing assessments conducted on 103 babies found 8 neonates had hearing disorders, of these 8 newborns 5 had conductive hearing loss and 3 had sensorineural hearing loss. Low birth weight and use of a ventilator significantly cause hearing loss.
Hearing loss was assessed as having no relationship with gestational age, sex, infection, and related diseases. Susyanto et al in 2014 conducted a study on risk factors for hearing loss from the results of hearing screening for babies in Yogyakarta and found that the most risk factors for deafness were hyperbilirubinemia with $53 \%$, prematurity $36.1 \%$, use of mechanical ventilation by $32.5 \%$. and LBW in the amount of $19.3 \%$. In fact, research on the relationship of these risk factors to the occurrence of congenital deafness has not been widely conducted in Indonesia. By conducting this study, it is hoped that the relationship between family history and congenital deafness, syndromes associated with sensorineural hearing loss, TORCH infection and prenatal syphilis, use of ototoxic drugs during pregnancy, prematurity, low birth weight, asphyxia, hyperbilirubinemia and congenital deafness in child. Based on the description above, the researchers determined the factors that are thought to have a role in congenital deafness in children so that diagnosis and selection of hearing habilitation can be carried out immediately. ${ }^{3,6,12,18}$

\section{Method}

This study is an analytical observational study using a cross-sectional design which aims to determine the relationship between family history factors and congenital deafness, syndromes associated with sensorineural hearing loss, TORCH infection and prenatal syphilis, use of ototoxic drugs during pregnancy, prematurity, low birth weight, asphyxia, hyperbilirubinemia with the incidence of congenital deafness in children at Dr. Mohammad Hoesin Palembang. A total of 349 research subjects participated in this study. The inclusion criteria were medical record data from all children who visited and underwent $\mathrm{OAE}$ and $\mathrm{ABR}$ examinations at the ENTKL polyclinic, Dr. Mohammad Hoesin Palembang during the period January 2019 - February 2021 with intact tympanic membrane and type A tympanometry.

In this study, data derived from all pediatric patients who underwent $\mathrm{OAE}$ and $\mathrm{ABR}$ examinations at the ENTKL polyclinic Dr. Mohammad Hoesin Palembang, taken from the Medical Record Installation 
of Dr. Mohammad Hoesin Palembang in the period January 2019 to February 2021. Medical record data of pediatric patients who underwent $\mathrm{OAE}$ and $\mathrm{ABR}$ examinations were taken in the form of demographic data (name, age and sex, method of delivery, and the presence or absence of risk factors for prematurity, asphyxia, weight. low birth weight, TORCH infection and intrauterine syphilis, hyperbilirubinemia, syndromes known to be associated with sensorineural hearing loss, ototoxic drugs during pregnancy, family history of congenital deafness with the results of OAE and ABR tests.

Univariate data analysis for each variable sex, type of delivery, prematurity, asphyxia, low birth weight, TORCH infection and intrauterine syphilis, congenital syndromes associated with sensorineural hearing loss, hyperbilirubinemia, ototoxic drugs during pregnancy, family history of congenital deafness with congenital deafness. This univariate analysis aims to describe the research sample. Descriptive analysis in the form of numerical data and categorical data. The numerical data will be presented in the form of a frequency distribution table, percentage and narrative. Data analysis of bivariate prematurity, asphyxia, low birth weight, TORCH infection and prenatal syphilis, hyperbilirubinemia, congenital syndromes known to be associated with sensorineural hearing loss, ototoxic drugs during pregnancy, family history of congenital deafness, with congenital deafness, each of which is a variable. categorical using the Chi-Square test. If the Chi-Square test conditions are not met, the Fisher test is used. Data from the results of statistical analysis are displayed in tabular form. Processing and data results will be assisted by SPSS software for windows version 22.0. Multivariate analysis was performed to analyze the relationship between many independent variables and a dependent variable. Logistic regression was used for categorical data. Multivariate analysis between congenital deafness and risk factors using a logistic regression model. For all statistical analyzes a significance limit of $\mathrm{p}<0.05$ was used.

\section{Results}

Data from 349 children as research subjects, it was found that the lowest age of children who underwent $\mathrm{OAE}$ and $\mathrm{ABR}$ examinations was 3 months and the highest was 195 months, with an average age of 35 months. Of the sample, 231 (66.2\%) boys and 118 $(33.8 \%)$ girls, were born with normal delivery method, $303(86.8 \%)$ samples and 46 (13.2\%) cesarean section. sample. There were 122 (35\%) children who had risk factors and 227 (65\%) children who did not have risk factors. For each risk factor, $6(1.7 \%)$ children with the youngest birth age were 28 weeks, 36 (10.3\%) asphyxia children, 41 (11.7\%) LBW children with the lowest weight of 1.050 grams, hyperbilirubinemia 20 (5.7\%) children, use of ototoxic drugs during pregnancy 14 (4\%) children, congenital syndromes associated with sensorineural hearing loss 28 (8\%) children, family history of congenital deafness of 7 (2\%) children, TORCH infection and syphilis during pregnancy in 32 (9.2\%) children.

The results of $\mathrm{OAE}$ and $\mathrm{ABR}$ examinations can be seen in Table 2. A total of 349 children who had been examined with $\mathrm{OAE}$ and ABR, obtained 180 (51.6\%) children with bilateral passes, 161 (46.1\%) children with bilateral referrals and $8(2.3 \%)$ children with unilateral referral results.

Distribution of the number of children with 122 (35\%) risk factors and 227 (65\%) children without risk factors, this is shown in Table 3.

The results of $\mathrm{OAE}$ and $\mathrm{ABR}$ examinations in children with risk factors and without risk factors can be seen in table 4 where out of 122 children with risk factors, $38(31.1 \%)$ children with bilateral pass results, $80(65.6 \%)$ children with results. bilateral referrals and $4(3.3 \%)$ children with unilateral referrals. Of the 227 neonates without risk factors, 142 (62.5\%) were children with bilateral pass results, 81 (35.7\%) children with bilateral referrals and $4(1.8 \%)$ children with unilateral referrals.

Based on table 5, it can be seen that the most common risk factors encountered were low birth weight (LBW), namely 15 (36.6\%) children with bilateral passes, 26 (63.4\%) bilateral referrals. Then other risk factors were prematurity in $6(3.3 \%)$ children, asphyxia in $36(19.5 \%)$ children, TORCH infection and syphilis during pregnancy in 32 (17.4\%) children, 
hyperbilirubinemia in $20(10.9 \%)$ children, use of ototoxic drugs during pregnancy in 14 (7.6\%) children, congenital syndrome of 28 (15.2\%) children, and family history of deafness in 7 (3.8\%) children.

The bivariate analysis in this study was aimed at looking at the relationship between risk factors and congenital deafness in children who underwent OAE and $\mathrm{ABR}$ examinations. The researcher performed a categorical comparative analysis using a 2x2 cross tab table, namely the Pearson Chi-square test and for data that did not meet the Chi-square requirements with a maximum expected count of less than 20\%, an alternative Fisher exact test would be performed. In this study, we categorized patients with unilateral referrals in the refer group so that bivariate data analysis could be carried out. The relationship between risk factors and the results of $\mathrm{OAE}$ and $\mathrm{ABR}$ examinations is shown in Table 6.

Of the 6 samples of children with risk factors for prematurity, $4(66.7 \%)$ were children with referral results and $2(33.3 \%)$ children with pass results. The results of the Chi square test showed that there was no significant relationship between prematurity and the results of $\mathrm{OAE}$ and $\mathrm{ABR}$ examinations $(\mathrm{p}=0.434)$.

Of children who had risk factors for asphyxia, 27 (75\%) children with referral results and 9 (25\%) children with pass results. From the results of the Chi square test, statistically, there was a significant relationship between asphyxia and the results of $\mathrm{OAE}$ and $A B R$ examinations ( $p=0.001)$. The results of the sample analysis were obtained in the asphyxia of the Odd Ratio (OR) value of 3.66 with a confidence level of 95\% CI, namely 1.667-8.036.

Low birth weight was found in 26 (63.4\%) children with referral results and 15 (36.6\%) children with pass results. The results of the Chi square test showed a significant relationship between low birth weight and the results of OAE and ABR examinations $(p=0.037)$. The results of this analysis were obtained in a sample with LBW OR value of 2.03 with a confidence level of 95\% CI, namely 1.033-3.975.

Risk factors for hyperbilirubinemia were found in 13 (65\%) children with referral results and 7 (35\%) children with pass results. The results of the Chi square test showed that there was no relationship between hyperbilirubinemia and the results of OAE and ABR tests $(p=0.120)$.

Children who had a family history of congenital deafness obtained the results of OAE and ABR examinations for $4(57.1 \%)$ referred children and 3 (42.9\%) pass children. The results of the Chi square test showed that there was no significant relationship between family history and congenital deafness with the results of OAE and ABR examinations $(p=0.715)$.

In the risk factors for congenital syndrome associated with sensorineural hearing loss, we found 28 children of which 20 (71.4\%) were referred to and 8 $(28.6 \%)$ had a pass. Chi square test results showed a significant relationship between congenital syndrome with $\mathrm{OAE}$ and ABR examination results $(\mathrm{p}=0.029)$, OR 2.44 with a confidence level of $95 \%$ CI 1.070-5.549.

Children whose parents were taking ototoxic drugs during pregnancy were found 13 (92.9\%) children with referral results and $1(7.1 \%)$ neonates with pass results. Chi square test results showed a significant relationship between the use of ototoxic drugs with the results of $\mathrm{OAE}$ and $\mathrm{ABR}$ tests $(\mathrm{p}=0.001)$. The results of this analysis were obtained in samples with ototoxic drugs with an OR value of 15.10 with a confidence level of 95\% CI, namely 1.953-116.715.

Of the 32 samples of children with risk factors for TORCH infection and syphilis during pregnancy, 27 $(84.4 \%)$ were children with referral results and 5 $(15.6 \%)$ children with pass results. The results of the Chi square test showed a significant relationship between asphyxia and the results of $\mathrm{OAE}$ and $\mathrm{ABR}$ examinations $(p=0.000)$. The results of this analysis were obtained in samples with an asphyxia OR value of 6.74 with a confidence level of $95 \% \mathrm{CI}$, namely 2.531 17.953.

Multivariate analysis in this study is to assess how the influence of the independent variables with the dependent variable. The analysis used is logistic regression with the backward LR method. In the variables that had a $\mathrm{p}$ value $<0.05$ from the previous bivariate analysis, six independent variables were selected, namely LBW, asphyxia, TORCH infection and syphilis during pregnancy, congenital syndromes 
associated with sensorineural hearing loss, use of ototoxic drugs during pregnancy and hyperbilirubinemia. The results of multivariate analysis are shown in table 7 where the strength of the relationship is seen from the adjusted odds ratio (ORadj), it is found that the variable use of ototoxic drugs during pregnancy has the strongest relationship with congenital deafness with an OR adj value of 9.65 then followed by the TORCH infection and syphilis variables. prenatals with congenital deafness with an OR adj value of 6.31 , the asphyxia variable with congenital deafness with an OR adj value of 3.09 and the congenital syndrome variable associated with sensorineural hearing loss with congenital deafness whose OR adj value was 2.42 .

The equation obtained is:

$$
\mathbf{Y}=\alpha+\beta_{1} \mathbf{X}_{1}+\beta_{2} \mathbf{X}_{2}+\beta_{3} \mathbf{X}_{3}
$$

Information:

$$
\begin{aligned}
& \mathbf{Y}=\text { Congenital deafness } \\
& \boldsymbol{\alpha}=\text { constant } \\
& \boldsymbol{\beta}_{\mathbf{1}}-\boldsymbol{\beta}_{\mathbf{n}}=\text { independent variable coefficient } \\
& \mathbf{X}_{\mathbf{1}}=\text { Ototoxic drug } \\
& \mathbf{X}_{\mathbf{2}}=\text { TORCH infection \& syphilis } \\
& \mathbf{X}_{\mathbf{3}}=\text { asphyxia } \\
& \mathbf{X}_{\mathbf{4}}=\text { Congenital syndrome }
\end{aligned}
$$

\begin{tabular}{|c|c|}
\hline Variable & $\mathbf{N}(\%)$ \\
\hline \multicolumn{2}{|l|}{ Gender } \\
\hline Male & $231(66.2)$ \\
\hline Female & $118(33.8)$ \\
\hline \multicolumn{2}{|l|}{ Type of childbirth } \\
\hline Normal & $303(86.8)$ \\
\hline Cesarean section & $46(13.2)$ \\
\hline \multicolumn{2}{|l|}{ Prematurity } \\
\hline Yes & $6(1.7)$ \\
\hline No & $343(98.3)$ \\
\hline \multicolumn{2}{|l|}{ Asphyxia } \\
\hline Yes & $36(10.3)$ \\
\hline No & $313(89.7)$ \\
\hline \multicolumn{2}{|l|}{ Low birth weight } \\
\hline Yes & $41(11.7)$ \\
\hline No & $308(88.3)$ \\
\hline \multicolumn{2}{|c|}{ TORCH infection \& gestational syphilis } \\
\hline Yes & $32(9.2)$ \\
\hline No & $317(90.8)$ \\
\hline \multicolumn{2}{|l|}{ Hyperbilirubinemia } \\
\hline Yes & $20(5.7)$ \\
\hline No & $329(94.3)$ \\
\hline \multicolumn{2}{|l|}{ Ototoxic drugs } \\
\hline Yes & $14(4)$ \\
\hline
\end{tabular}

Then put in the probability formula

$$
\mathrm{P}=1 /(1+\mathrm{EXP}(-\mathrm{Y}))
$$

By including the four factors above, the probability or chance of congenital deafness is $99.6 \%$ and with the three risk factors and the following can be seen in the table below:

Table 1 Basic characteristics of research samples 
Family history of congenital deafness

$$
\begin{aligned}
& \text { Yes } \\
& \text { No }
\end{aligned}
$$

Congenital Syndrome

Yes

No

$321(92)$

Table 2 OAE and ABR examination results

\begin{tabular}{lcc}
\hline Examination results & $\mathbf{N}$ & $\%$ \\
\hline Bilateral pass & 180 & 51.6 \\
Bilateral refer & 161 & 46.1 \\
Unilateral refer & 8 & 2.3 \\
\hline Total & 349 & 100 \\
\hline
\end{tabular}

Table 3 Sample Distribution based on risk factors

\begin{tabular}{lcc}
\hline Risk factor & N & $\%$ \\
\hline Risk factor $(+)$ & 122 & 35 \\
Risk factor $(-)$ & 227 & 65 \\
\hline Total & 349 & 100 \\
\hline
\end{tabular}

Table 4 Examination results of children with risk factors and without risk factors

\begin{tabular}{lccccccccc}
\hline \multirow{2}{*}{ Risk factor } & \multicolumn{4}{c}{ Examination result } & \multicolumn{2}{c}{ Total } \\
\cline { 2 - 7 } & \multicolumn{2}{c}{ Bilateral pass } & Bilateral refer & Unilateral refer & & \\
\cline { 2 - 7 } & $\mathbf{N}$ & $\%$ & $\mathbf{N}$ & $\%$ & $\mathbf{N}$ & $\%$ & $\mathbf{N}$ & $\%$ \\
\hline Risk factor (+) & 38 & 31.1 & 80 & 65.6 & 4 & 3.3 & 122 & 35 \\
Risk factor (-) & 142 & 62.5 & 81 & 35.7 & 4 & 1.8 & 227 & 65 \\
\hline Total & 180 & 51.6 & 161 & 46.1 & 8 & 2.3 & 349 & 100 \\
\hline
\end{tabular}

\begin{tabular}{|c|c|c|c|c|c|c|c|c|}
\hline \multirow{3}{*}{ Risk factor } & \multicolumn{6}{|c|}{ Examination result } & \multirow{2}{*}{\multicolumn{2}{|c|}{ Total }} \\
\hline & \multicolumn{2}{|c|}{ Bilateral pass } & \multicolumn{2}{|c|}{ Bilateral refer } & \multicolumn{2}{|c|}{ Unilateral refer } & & \\
\hline & $\mathbf{N}$ & $\%$ & $\mathbf{N}$ & $\%$ & $\mathbf{N}$ & $\%$ & $\mathbf{N}$ & $\%$ \\
\hline Prematurity & 2 & 33.3 & 4 & 66.7 & 0 & 0 & 6 & 3.3 \\
\hline Asphyxia & 9 & 25 & 27 & 75 & 0 & 0 & 36 & 19.5 \\
\hline Low birth weight & 15 & 36.6 & 26 & 63.4 & 0 & 0 & 41 & 22.3 \\
\hline TORCH \& syphilis & 5 & 15.6 & 27 & 84.4 & 0 & 0 & 32 & 17.4 \\
\hline Hyperbilirubinemia & 7 & 35 & 13 & 65 & 0 & 0 & 20 & 10.9 \\
\hline Ototoxic drugs & 1 & 7.1 & 12 & 85.8 & 1 & 7.1 & 14 & 7.6 \\
\hline Congenital syndrome & 8 & 28.6 & 17 & 60.7 & 3 & 10.7 & 28 & 15.2 \\
\hline
\end{tabular}

Table 5 Distribution of risk factors for congenital deafness and examination results 


\begin{tabular}{lcccccccc}
\hline Family history of congenital deafness & 3 & 42.9 & 4 & 57.1 & 0 & 0 & 7 & 3.8 \\
\hline Total & 50 & 27.2 & 130 & 70.6 & 4 & 2.2 & 184 & 100 \\
\hline
\end{tabular}

Table 6 Relationship between risk factors and congenital deafness.

\begin{tabular}{|c|c|c|c|c|c|c|c|c|}
\hline \multirow{3}{*}{ Risk factor } & \multicolumn{4}{|c|}{ Examination result } & \multirow{3}{*}{$\mathbf{p}$} & \multirow{3}{*}{ OR } & \multirow{2}{*}{\multicolumn{2}{|c|}{ 95\% CI }} \\
\hline & \multicolumn{2}{|c|}{ Refer } & \multicolumn{2}{|c|}{ Pass } & & & & \\
\hline & $\mathbf{N}$ & $\%$ & $\mathbf{N}$ & $\%$ & & & Lower & Upper \\
\hline \multicolumn{9}{|l|}{ Prematurity } \\
\hline Yes & 4 & 66.7 & 2 & 33.3 & \multirow{2}{*}{$0.434^{b}$} & \multirow{2}{*}{2.183} & \multirow{2}{*}{0.395} & \multirow{2}{*}{12.076} \\
\hline No & 164 & 47.8 & 179 & 52.2 & & & & \\
\hline \multicolumn{9}{|l|}{ Asphyxia } \\
\hline Yes & 27 & 75 & 9 & 25 & \multirow{2}{*}{$0.001^{\mathrm{a}}$} & \multirow{2}{*}{3.660} & \multirow{2}{*}{1.667} & \multirow{2}{*}{8.036} \\
\hline No & 141 & 45 & 172 & 55 & & & & \\
\hline \multicolumn{9}{|c|}{ Low birth weight } \\
\hline Yes & 26 & 63.4 & 15 & 36.6 & \multirow{2}{*}{$0.037^{a}$} & \multirow{2}{*}{2.026} & \multirow{2}{*}{1.033} & \multirow{2}{*}{3.975} \\
\hline No & 142 & 46.1 & 168 & 53.9 & & & & \\
\hline \multicolumn{9}{|c|}{ Hyperbilirubinemia } \\
\hline Yes & 13 & 65 & 7 & 35 & \multirow{2}{*}{$0.120^{\mathrm{a}}$} & \multirow{2}{*}{2.085} & \multirow{2}{*}{0.811} & \multirow{2}{*}{5.358} \\
\hline No & 155 & 47.1 & 174 & 52.9 & & & & \\
\hline \multicolumn{9}{|c|}{ Family history } \\
\hline Yes & 4 & 57.1 & 3 & 42.9 & \multirow{2}{*}{$0.715^{b}$} & \multirow{2}{*}{1.447} & \multirow{2}{*}{0.139} & 6562 \\
\hline No & 164 & 48 & 178 & 52 & & & & 0.000 \\
\hline Syndrome & & & & & & & & \\
\hline Yes & 20 & 71.4 & 8 & 28.6 & ค ควดа & 0427 & 1970 & 550 \\
\hline No & 149 & 46.4 & 172 & 53.6 & $0.029^{\circ}$ & 2.431 & 1.070 & 0.049 \\
\hline Ototoxic dru & & & & & & & & \\
\hline Yes & 13 & 92.9 & 1 & 7.1 & ด 001 a & 15097 & 1050 & 116715 \\
\hline No & 155 & 46.3 & 180 & 53.7 & 0.0014 & 10.091 & 1.900 & 110.110 \\
\hline TORCH infe & & & & & & & & \\
\hline Yes & 27 & 84.4 & 5 & 15.6 & $\cap \cap \cap \cap$ a & 6740 & 2531 & 17053 \\
\hline No & 141 & 44.5 & 176 & 55.5 & $0.000^{\circ}$ & 0.140 & 2.031 & 17.900 \\
\hline
\end{tabular}

aChi-square pearson

${ }^{b}$ Fisher exact test

Table 7 Logistic regression results of risk factors associated with the incidence of congenital deafness

\begin{tabular}{lcccc}
\hline Faktor Risiko & $\begin{array}{c}\text { Coefficient } \\
\text { (B) }\end{array}$ & P value & OR & CI95\% \\
\hline Asphyxia & 1.129 & 0.007 & 3.091 & $1.353-7.064$ \\
TORCH infection \& syphilis & 1.843 & 0.000 & 6.315 & $2.329-17.122$ \\
Congenital Syndrome & 0.883 & 0.043 & 2.419 & $1.027-5.699$ \\
Ototoxic drugs & 2.267 & 0.033 & 9.651 & $1.197-77.816$ \\
Contant & -0.453 & 0.000 & 0.636 & - \\
\hline
\end{tabular}

* Tested with backward LR method logistic regression 
Table 8 Probability of congenital deafness

\begin{tabular}{lcc}
\hline Risk Factor & Y & Probability \\
\hline $\mathrm{X}_{1}+\mathrm{X}_{2}+\mathrm{X}_{3}+\mathrm{X}_{4}$ & 5.660 & 0.996 \\
$\mathrm{X}_{1}+\mathrm{X}_{2}+\mathrm{X}_{3}$ & 4.770 & 0.991 \\
$\mathrm{X}_{1}+\mathrm{X}_{2}$ & 3.648 & 0.974 \\
$\mathrm{X}_{1}$ & 1.814 & 0.859 \\
Constant & -0.453 & \\
\hline
\end{tabular}

\section{Discussion}

The most risk factors for children in this study were LBW, namely 41 (22.3\%) children. Then followed by other risk factors, namely asphyxia $36(19.5 \%)$ children, TORCH infection and prenatal syphilis 32 (17.4\%) children, congenital syndromes associated with sensorineural hearing loss 28 (15.2\%) children, hyperbilirubinemia 20 (10.9\%) children, the use of ototoxic drugs during pregnancy for 14 (7.6\%) children, family history of $7(3.8 \%)$ children with congenital deafness and $6(3.3 \%)$ children prematurity. In this study, there were 41 children with LBW risk factors, 15 (36.6\%) children with bilateral passes, 26 (63.4\%) children with bilateral referrals and no unilateral referrals were found. Purnomo conducted research at Sardjito Hospital Yogyakarta in 2011 in his study of 64 LBW children, the results of OAE referrals were obtained for 20 children. Based on the research conducted by Aruan et al. In Medan, there were 21 infants with birth weight $<1.500 \mathrm{gr}$ as many as 6 babies $(28.6 \%)$ refer, while from 11 babies with birth weight> 1,500 gr, there were 2 babies $(18.2 \%)$ refer. With the Chi-Square test, there was no significant relationship between DPOAEs results and birth weight $(p=0.519)$. Meanwhile, the results of our study's Chi square test showed a significant relationship between LBW and congenital deafness $(p=0.037)$. The results of this analysis were obtained in a sample with LBW OR value of 2.03 with a confidence level of $95 \%$ CI, namely 1.033-3.975. Low birth weight indicates that intrauterine fetal development is not optimal. This affects intrauterine development and the central nervous system. Infants with low birth weight will experience developmental delays including hearing loss, possibly due to neurological and sensory development disorders. ${ }^{18.19}$

The risk factors for asphyxia were 36 children, 9
(25\%) children with bilateral passes, 27 (75\%) children with bilateral referrals and no children with unilateral referrals were found. Amini et al. Studied 149 neonates with asphyxia, 38 (25.5\%) neonates with referral results. Lakshmi et al's study conducted ABR examinations on 37 neonates with asphyxia with an APGAR score $<6$, it was found that 7 neonates had no response to the ABR examination, hearing loss in neonates with asphyxia was six times more likely to occur than without asphyxia. . In the bivariate analysis of 36 samples of children with risk factors for asphyxia, 27 (55.6\%) children with referral results and 9 (44.4\%) children with pass results. Chi square test results showed a significant relationship between asphyxia and congenital deafness ( $p=0.001$ ). The results of this analysis were obtained in samples with an asphyxia OR value of 3.66 with a confidence level of 95\% CI, namely 1.667-8.036. Oxygenation and perfusion are important in maintaining inner ear function. Neonatal asphyxia can cause degeneration of the inner ear, loss of outer and inner hair cells, and degeneration of spiral and vestibular ganglion cells. ${ }^{17.18}$

The risk factors for TORCH infection and prenatal syphilis were 32 children, 5 (15.6\%) children with bilateral passes, 27 (84.4\%) children with bilateral referrals and no children with unilateral referrals were found. Thakkar et al studied 60 children with risk factors, only 2 children with risk factors for TORCH infection and prenatal syphilis and 1 child with congenital deafness. The study by Poonual et al. Examined 135 neonates exposed to aminoglycoside drugs, found 77 neonates with the results of the referral examination. In a bivariate analysis of 32 samples of children with risk factors for TORCH infection and prenatal syphilis, $27(84.4 \%)$ children with referral results and $5(15.6 \%)$ children with pass results. Chi square test results showed a significant relationship 
between TORCH infection and prenatal syphilis with congenital deafness $(\mathrm{p}=0.000)$. The results of this analysis were obtained in samples with TORCH infection and prenatal syphilis OR value of 6.74 with a confidence level of $95 \% \mathrm{CI}$, namely $2.531-17.953$. This is in accordance with the theory that transmission of TORCH infection and prenatal syphilis to the fetus via the placenta, the virus causes direct cochlear damage and cell death of cortiary organs and vascular stria, resulting in sensorineural hearing loss. ${ }^{20}$

Hearing loss characterized by additional clinical manifestations as part of a particular set of symptoms (syndromic hearing loss), or as a non-syndromic hearing loss. In this study, the risk factors for congenital syndrome associated with sensorineural hearing loss were 28 children, 8 (28.6\%) children with bilateral passes, $17(60.7 \%)$ children with bilateral referrals and found $3(10.7 \%)$. ) children with unilateral refer. Imam et al studied 100 children, found 8 children with congenital syndrome and 2 (25\%) children with sensorineural deafness. Thakkar et al's study on 60 children with risk factors, found 2 children with congenital syndrome and 2 children experienced congenital deafness. In the bivariate analysis of 28 samples of children with risk factors for congenital syndrome, 20 (71.4\%) children with referral results and $8(28.6 \%)$ children with pass results. Chi square test results showed a significant relationship between congenital syndromes associated with sensorineural hearing loss and congenital deafness ( $\mathrm{p}=$ 0.029). The results of this analysis were obtained in samples with congenital syndrome OR value of 2.44 with a confidence level of $95 \%$ CI, namely $1.070-8.549 .3,20$

The risk factors for hyperbilirubinemia were 20 children, 7 (35\%) children with bilateral passes and 13 (65\%) children with bilateral referrals. Susyanto conducted a study on 83 neonates, found 44 neonates with hyperbilirubinemia, 21 neonates with hyperbilirubinemia with the results of the OAE refer examination. The study by Boskabadi et al. Stated that hearing loss occurs about 10-50 times more frequently in neonates with severe jaundice. Total bilirubin levels had the highest predictability for the infant's hearing status. Blood type and Rhesus incompatibility between mother and child and G6PD deficiency are important known causes for hearing loss due to jaundice. In the bivariate analysis of 20 samples with risk factors for hyperbilirubinemia, 13 (65\%) children with referral results and 7 (35\%) children with pass results. Chi square test results showed no relationship between hyperbilirubinemia and congenital deafness ( $p=0.120)$. Based on the theory that the level of unconjugated bilirubin in serum exceeds the binding capacity of albumin, this non-binding and fat-soluble bilirubin will cross the blood-brain barrier, which can lead to neurological sequelae, including sensorineural deafness, in this study different which can be caused by less number of samples. 18.20

The risk factors for using ototoxic drugs during pregnancy were 14 children, 1 (7.1\%) children with bilateral passes, $12(85.7 \%)$ children with bilateral referrals and 1 (7.1\%) children with unilateral referrals. Poonual et al's study of 135 neonates exposed to aminoglycoside drugs found 77 neonates with the results of the referral examination. In the bivariate analysis of 21 samples of neonates with risk factors for ototoxic drugs, 13 (92.9\%) children with referral results and 1 $(7.1 \%)$ children with pass results. Chi square test results showed a significant relationship between the use of ototoxic drugs during pregnancy and congenital deafness $(p=0.001)$. The results of this analysis were obtained in samples with ototoxic drugs during pregnancy with an OR value of 15.10 with a confidence level of $95 \% \mathrm{CI}$, namely 1.953-116.715. Ototoxic drugs include aminoglycosides, loop diuretics can cause hearing loss by damaging cochlear cells or external hair, due to the concentration of the drug in the perilymph fluid.26.27

More than $50 \%$ of prelingual deafness is genetic, deafness occurs because the ear organs do not develop normally, for example the cochlea does not develop normally or dysgenesis of cortiary organs which is an autosomal disorder, both dominant and recessive. Family history of congenital deafness was obtained in 7 children, with 3 (42.9\%) children with bilateral passes and $4(5.1 \%)$ children with bilateral referrals. Thakkar et al's study on 60 children with risk factors, found 2 children with a family history of congenital deafness and 1 of these children had congenital deafness. Imam et al's study conducted an examination of 100 neonates with 
50 children who had multiple risk factors, found 2 children with risk factors for family history and both of them were not congenital deaf. In the bivariate analysis of 7 samples with risk factors for family history of congenital deafness, 4 (57.1\%) children with referral results and $3(42.9 \%)$ children with pass results. The results of the Chi square test showed that there was no significant relationship between family history and congenital deafness with the results of $\mathrm{OAE}$ and $\mathrm{ABR}$ examinations $(p=0.715)$. This may be due to in-depth family history history or because the child's parents do not understand the definition of these risk factors, the small number of samples and the absence of objective examinations and genetic examinations to confirm the presence of these risk factors. ${ }^{3,20}$

Premature babies severely lack preparation for extrauterine life, namely maturity of organ system function. Premature babies tend to be prone to hypothermia, respiratory distress, hypoglycemia, infections, hyperbilirubinemia. The development of intrauterine nerves is immature, thus increasing the risk of abnormalities in both the anatomical structure and function of the auditory nerve. In this study, 6 children were born prematurely, 2 (33.3\%) children with bilateral pass results, $4(66.7 \%)$ children with bilateral referrals and no children with unilateral referrals were found. Meqbel's study of 200 babies with risk factors for hearing loss found 23 babies with hearing loss and 10 of them were preterm babies $<30$ weeks of gestation. Bhagya et al's study found 17 babies with hearing loss out of 25 preterm infants, and 10 of them with very severe sensory neural hearing loss. In the bivariate analysis of 19 samples of neonates with risk factors for prematurity, 4 $(66.7 \%)$ children with referral results and 2 (33.3\%) children with pass results. Chi square test results showed that there was no significant relationship between prematurity and congenital deafness $(\mathrm{p}=$ 0.434). This is different from the literature which may be caused by a less in-depth family history, the age of the children who are the sample is less homogeneous, and the number of samples is insufficient.29,30

To see the strength of the relationship between risk factor variables and congenital deafness in children, a multivariate analysis was performed with logistic regression on variables with $\mathrm{p}$ value $<0.25$. The logistic regression results show that the risk factors for ototoxic drugs during pregnancy have the strongest association with congenital deafness with the risk for congenital deafness up to 9.65 times, the risk factors for TORCH infection and prenatal syphilis have a relationship with congenital deafness with the risk for experiencing Congenital deafness up to 6.31 times, risk factors for asphyxia have an association with congenital deafness with a risk for congenital deafness up to 3.09 times, risk factors for congenital deafness associated with sensorineural hearing loss have an association with congenital deafness with a risk for experiencing congenital deafness up to 2.42 times and if there are conditions where the subject has the four factors above, the probability or chance of congenital deafness is 99.6\%. In subjects who have 3 risk factors (ototoxic drugs during pregnancy, TORCH infection and prenatal syphilis and asphyxia) above, the probability or chance of congenital deafness is $99.1 \%$. In subjects who had 2 risk factors (ototoxic drugs during pregnancy and TORCH infection and prenatal syphilis) above, the probability or chance of congenital deafness was $97.4 \%$. In subjects who only had risk factors for ototoxic drugs during pregnancy, the probability or chance of congenital deafness was $85.9 \%$. In Bhagya et al's study we can observe that infants exposed to risk factors such as preterm labor, neonatal jaundice, neonatal seizures, birth asphyxia \& LBW are prone to hearing loss. These risk factors are neonatal seizure, birth asphyxia \& neonatal jaundice having a very high risk for hearing loss. So hearing loss must be detected at an early stage and appropriate rehabilitation measures must be taken immediately so that further development of the child is not disturbed. ABR as a screening procedure will help provide an idea of the degree of hearing loss. Poonual's study concluded that low birth weight, APGAR score $<6$ in the first 5 minutes, craniofacial anomalies, sepsis, and ototoxic exposure are risk factors for bilateral hearing loss in infants ( 3 months of age) and appropriate examinations should be performed to identify risk factors. this. As a result for now, it is recommended that hospitals, general practitioners, health facilities, polyclinics should carry out universal hearing checks on 
all babies before 36 weeks. Screening programs are important for the prevention of disability and for improving people's quality of life. ${ }^{3,18}$

The limitation of this study is that there are actually many risk factors associated with the occurrence of congenital deafness, but in this study only a few factors were analyzed due to limited data on medical records and the limited accuracy of the history data due to not being an objective examination result. Some of the factors that were not included in this study included postnatal risk factors such as meningitis and postnatal temporal trauma. In the analysis of risk factors for prematurity and family history with congenital deafness, it was found that statistically there was no relationship with the incidence of congenital deafness, possibly because the history of the family history was not in-depth or because the child's parents did not understand the limitations of the definition of these risk factors, the number of samples was less and the absence of objective examination and genetic testing to confirm the presence of these risk factors.

\section{Conclusion}

There is a significant relationship between risk factors for ototoxic drugs during pregnancy, TORCH and syphilis infection during pregnancy, asphyxia, congenital syndrome, LBW and hyperbilirubinemia with congenital deafness.

\section{References}

1. Korver AM, Smith RJ, Van Camp G dkk. Congenital hearing loss. Nat Rev Dis Primers. 2017; 3:16094. Published 2017 Jan 12.

2. Gutler N, Gysin C, Schmid N dkk. Bilateral congenital deafness: what investigations should be performed A qualitative descriptive review. Swiss Medical Weekly. Swiss. 2017.

3. Imam S S, Farrash R A, Taha H M, dkk. Targeted versus Universal Neonatal Hearing Screening in a Single Egyptian Center. Hindawi Publishing Corporation. Egypt. 2013.

4. Gupta A, Sukumar V. Targeted Newborn Hearing Screening: A Hospital based Observational
Study. International Journal of Contemporary Medical Research. India. 2019. Vol 6. Hal 10.

5. Ministry of Health RI. Republic of Indonesia Ministry of Health Circular number HK. 02.02 / $\mathrm{V} / 553 / 2017$ regarding the commemoration of World Hearing Day 2017. www.kemkes.go.id. March 1st.

6. Ghanie A, Memy YD, Sari SN. Angka Kejadian Delayed Speech Disertai Gangguan Pendengaran pada Anak yang Menjalani Pemeriksaan Pendengaran di Bagian Neurootologi IKTHT-KL RSUP Dr. Moh. Hoesin. Jurnal kedokteran dan kesehatan, volume 2, no. 1, Januari 2015: 121-127.

7. Tortora G J, Derrickson B, Burkett B et al. Principles of Anatomy and Physiology. 1 ${ }^{\text {st }}$ AsiaPacific ed. USA: John Wiley \& Sons Inc; 2016. Hal 611-624.

8. Marieb E N, Hoehn K. Essentials of Human Anatomy \& Physiology. 9th ed. Redwood City, Calif: Benjamin/Cummings Pub. Co. 2013. Hal 570-584.

9. Wineski LE. Snell's Clinical anatomy by regions: Head and Neck. 10 th ed. Philadelphia: Walters Kluwer; 2019. Hal 1713-1716.

10. Lee, K. J. Congenital Hearing Loss. Dalam: Chan Y, Goddard J, editor. Essential Otolaryngology: Head \& Neck Surgery. Edisi 12. New York: The McGraw-Hill, Medical Pub. Division; 2019. hal 334.

11. Muyassaroh. Early Detection and Habilitation of Hearing Disorders in Infants and Children. Med Hosp 2017; vol 4 (2): 139-142.

12. Mehar V, Somani P, Singh K dkk. Targeted hearing screening in newborns. International Journal of Contemporary Pediatrics. India.2016. ;3(1):159-163.

13. Rundjan L, Amir I, Suwento R, Mangunatmadja I. Hearing Loss Screening in High-Risk Neonates. Sari Pediatrics. 2005.6 (4): 149-54.

14. Community ENT Module, Collegium of Ear, Nose, Throat, Head and Neck Surgery, 2015. 
15. Azwar. Early Detection of Hearing Loss in Children. Syiah Kuala Medical Journal. Banda Aceh. 2013. Volume 13. JKS 2013; 1: 59-64.

16. Joint Commttee on Infant Hearing (JCIH). The Jounal of Early Hearing Detection and Intervention, Year 2019 Position Statemen t: Principles and Guidelines for Early Hearing Detection and Intervention Programs Pediatrics. 2019. 4 (2) :1-44.

17. Kusumagani H, Purnami N. Newborns Hearing Screening with Otoacoustic Emissions and Auditory Brainstem Response. J Community Med Pub Health Res. Surabaya. 2020. Vol 1, No 1

18. Susyanto, Bambang, \& Asti Widuri. Risk Factors for Hearing Loss in Newborn Hearing Screening at PKU Muhammadiyah Yogyakarta Hospital. Mutiara Medika: Journal of Medicine and Health [Online], 15.1 (2015): 30 - 36

19. Uhlén. OAEs, Otoacoustic Emissions and I. "Guide to Audiology and Hearing Aids for Otolaryngologists Otoacoustic Emissions (OAEs)." (2017).

20. Thakkar D, Barot D. Brainstem-Evoked Response Audiometry in Pediatric Age Group. Indian J Otol. 2018; 24:246-51.

21. Hall JW. eHandbook of Auditory Evoked Responses. USA: Pearson Education Inc; 2015.

22. Wijana, Syamsuddin A, Dewi Y A. Gelombang Auditory Brainstem Response (ABR) pada Anak di Bawah Lima Tahun. MKB. Bandung. 2014. Volume 46 No. 3 p. 183.

23. Ferdiansyah R, Damayanti H, Rosalina D dkk. Development of Diagnostic and Hearing Loss and Communication Centers at Fatmawati Hospital, Jakarta. Fatmawati Hospital. Jakarta. 2016. Volumes 1-04.

24. British Society of Audiology (2019), Practice Guidance Behavioural Observational Audiometry, [Online]. Available from: www.thebsa.org.uk. [2019/04].

25. Allen SB, Goldman J. Syndromic Sensorineural Hearing Loss. [Updated 2020 Aug 24]. In: StatPearls [Internet]. Treasure Island (FL):
StatPearls Publishing; 2020 Jan-. Available from:

https://www.ncbi.nlm.nih.gov/books/NBK526 $\underline{088}$.

26. Griffith A J, Friedman T B. Hereditary Hearing Loss. Dalam SNOW, J. B., WACKYM, P. A., \& BALLENGER, J. J editor. Ballenger's otorhinolaryngology: head and neck surgery. Shelton, Conn, People's Medical Pub. House/B C Decker.18th ed.2016. p1077.

27. Kenna MA. Nongenetic Hearing Loss. BJ Bailey, JT Johnson, \& SD Newland (5th eds), Head \& neck surgery - otolaryngology, Lippincott Williams \& Wilkins, Texas. 2014. P.1523.

28. Nugroho DA, Muyassaroh. Tuli Kongenital Diduga Akibat Infeksi Rubela dan Sitomegalovirus. Med Hospital. Semarang. 2014. Vol 2 (2): 130-136.

29. Meqbel AA, Baghli HA. The Prevalence of Hearing Impairment in High-Risk Infants in Kuwait. Aud Vest Res. 2015. 24(1):11-16.

30. Hirvonen M, Ojala R, Korhonen P, Haataja P, Eriksson K, Gissler M dkk. Visual and Hearing Impairment After Preterm Birth. Pediatrics. 2018; 142(2): e20173888. 